\title{
Development and Validation of CAGIB Score for Evaluating the Prognosis of Cirrhosis with Acute Gastrointestinal Bleeding: A Retrospective Multicenter Study
}

\author{
Zhaohui Bai - Bimin Li - Su Lin · Bang Liu - Yiling Li - Qiang Zhu • \\ Yunhai $\mathrm{Wu} \cdot$ Yida Yang $\cdot$ Shanhong Tang $\cdot$ Fanping Meng $\cdot$ Yu Chen \\ Shanshan Yuan $\cdot$ Lichun Shao $\cdot$ Xingshun Qi (i)
}

Received: July 25, 2019/ Published online: September 11, 2019

(C) The Author(s) 2019

\section{ABSTRACT}

Introduction: Acute gastrointestinal bleeding (GIB) is a major cause of death in liver cirrhosis. This multicenter study aims to develop and validate a novel and easy-to-access model for predicting the prognosis of patients with cirrhosis and acute GIB.

Zhaohui Bai, Bimin Li, Su Lin, and Bang Liu contributed equally to this work.

Enhanced Digital Features To view enhanced digital features for this article go to https://doi.org/10.6084/ m9.figshare.9741731.

\section{Z. Bai · X. Qi ( $₫)$}

Department of Gastroenterology, General Hospital of Northern Theater Command (formerly called General Hospital of Shenyang Military Area),

Shenyang, China

e-mail: xingshunqi@126.com

B. $\mathrm{Li}$

Department of Gastroenterology, First Affiliated Hospital of Nanchang University, Nanchang, China

S. Lin

Liver Research Center, First Affiliated Hospital of

Fujian Medical University, Fuzhou, China

B. Liu

Department of Hepatobiliary Disease, 900 Hospital of the Joint Logistics Team (formerly called Fuzhou General Hospital), Fuzhou, China
Methods: Patients with cirrhosis and acute GIB were enrolled and randomly divided into the training $(n=865)$ and validation $(n=817)$ cohorts. In the training cohort, the independent predictors for in-hospital death were identified by logistic regression analyses, and then a new prognostic model (i.e., CAGIB score) was established. Area under curve (AUC) of CAGIB score was calculated by receiver operating characteristic curve analysis and compared with Child-Pugh, model for end-stage liver disease (MELD), MELD-Na, and neutrophil-lymphocyte ratio (NLR) scores.

Results: In the training cohort, hepatocellular carcinoma (HCC), diabetes, total bilirubin (TBIL), albumin (ALB), alanine aminotransferase (ALT),

Y. Li

Department of Gastroenterology, First Affiliated Hospital of China Medical University, Shenyang, China

Q. Zhu

Department of Gastroenterology, Shandong Provincial Hospital Affiliated to Shandong

University, Jinan, China

Y. Wu

Department of Critical Care Medicine, Sixth

People's Hospital of Shenyang, Shenyang, China 
and serum creatinine $(\mathrm{Scr})$ were independent predictors of in-hospital death. CAGIB score $=$ diabetes $\quad($ yes $=1, \quad$ no $=0) \times 1.040+$ HCC (yes $=1$, no $=0) \times 0.974+$ TBIL $(\mu \mathrm{mol} /$ $\mathrm{L}) \times 0.005-\mathrm{ALB} \quad(\mathrm{g} / \mathrm{L}) \times 0.091+\mathrm{ALT} \quad(\mathrm{U} /$ $\mathrm{L}) \times 0.001+\mathrm{Scr}(\mu \mathrm{mol} / \mathrm{L}) \times 0.012-3.964$. In the training cohort, the AUC of CAGIB score for predicting in-hospital death was 0.829 (95\% CI $0.801-0.854, P<0.0001)$, which was higher than that of Child-Pugh $(0.762,95 \%$ CI 0.732-0.791), MELD (0.778, 95\% CI 0.748-0.806), MELD-Na (0.765, 95\% CI 0.735-0.793), and NLR (0.587, 95\% CI 0.553-0.620) scores. In the validation cohort, the AUC of CAGIB score $(0.714,95 \%$ CI 0.682-0.746, $P=0.0006)$ remained higher than that of Child-Pugh $(0.693,95 \%$ CI 0.659-0.725), MELD (0.662, 95\% CI 0.627-0.695), MELD-Na (0.660, 95\% CI 0.626-0.694), and NLR (0.538, 95\% CI 0.503-0.574) scores.

Conclusion: CAGIB score has a good predictive performance for prognosis of patients with cirrhosis and acute GIB.

Keywords: Child-Pugh; Cirrhosis; Gastrointestinal bleeding; MELD; Prognosis

Y. Yang

State Key Laboratory for Diagnosis and Treatment of Infectious Diseases, Collaborative Innovation Center for Diagnosis and Treatment of Infectious Diseases, First Affiliated Hospital, College of Medicine, Zhejiang University, Hangzhou, Zhejiang, China

S. Tang

Department of Gastroenterology, General Hospital of Western Theater Command, Chengdu, China

F. Meng

Department of Biological Therapy, Fifth Medical Center of PLA General Hospital, Beijing, China

Y. Chen

Difficult and Complicated Liver Diseases and Artificial Liver Center, Beijing Youan Hospital, Capital Medical University, Beijing, China

S. Yuan

Department of Gastroenterology, Xi'an Central Hospital, Xi'an, China

L. Shao

Department of Gastroenterology, Air Force Hospital of Northern Theater Command, Shenyang, China

$\begin{array}{ll}\text { Abbreviations } \\ \text { AKP } & \text { Alkaline phosphatase } \\ \text { ALB } & \text { Albumin } \\ \text { ALT } & \text { Alanine aminotransferase } \\ \text { AUC } & \text { Area under curve } \\ \text { CAGIB } & \text { Cirrhosis acute gastrointestinal } \\ & \text { bleeding } \\ \text { CIs } & \text { Confidence intervals } \\ \text { GBS } & \text { Glasgow-Blatchford score } \\ \text { GGT } & \text { Gamma-glutamyl transpeptidase } \\ \text { GIB } & \text { Gastrointestinal bleeding } \\ \text { Hb } & \text { Hemoglobin } \\ \text { HCC } & \text { Hepatocellular carcinoma } \\ \text { HCT } & \text { Hematocrit } \\ \text { HE } & \text { Hepatic encephalopathy } \\ \text { INR } & \text { International normalized ratio } \\ \text { K } & \text { Potassium } \\ \text { MELD } & \text { Model for end-stage liver disease } \\ \text { Na } & \text { Sodium } \\ \text { NLR } & \text { Neutrophil-lymphocyte ratio } \\ \text { ORs } & \text { Odds ratios } \\ \text { PLT } & \text { Platelet } \\ \text { Scr } & \text { Serum creatinine } \\ \text { TBIL } & \text { Total bilirubin } \\ \text { WBC } & \text { White blood cell }\end{array}$

INTRODUCTION

Acute gastrointestinal bleeding (GIB) is an emergency and critical clinical event [1]. The mortality of acute GIB is $6-20 \%$ in patients with cirrhosis [2-4]. The prognosis seems to be similar between patients with cirrhosis and acute variceal bleeding and those with cirrhosis and peptic ulcer bleeding [5]. It is important to accurately evaluate the prognosis in patients with cirrhosis and acute GIB. Conventional scoring systems for assessing the prognosis of patients with acute GIB mainly include Rockall score [6], Glasgow-Blatchford score (GBS) [7], and AIMS65 score [8]. However, they are not specific for patients with cirrhosis in whom gastroesophageal varices are the most frequent sources of acute GIB [9] and the severity of liver dysfunction is closely associated with patients' outcomes. On the other hand, Child-Pugh [10], model for end-stage liver disease (MELD) [11], MELD-Na [12], and neutrophil-lymphocyte 
ratio (NLR) [13] scores have been widely employed for prognostic assessment in general patients with liver cirrhosis. But their predictive performances remain suboptimal in patients with cirrhosis and acute GIB.

The present work aimed to develop and validate a novel model for assessing the prognosis of patients with cirrhosis and acute GIB on the basis of the data obtained from a multicenter study.

\section{METHODS}

The present study was based on the TORCH study (NCT03846180), which was an investigator-initiated multicenter study across 13 centers from eight provinces or municipalities in China. It was carried out following the rules of the Declaration of Helsinki and was approved by the Medical Ethical Committee of the General Hospital of Northern Theater Command (formerly General Hospital of Shenyang Military Area), which is the principal affiliation of this study. The ethical approval number was $\mathrm{k}(2019) 20$. The requirement for informed written consent was waived because of the nature of this study. Briefly, we enrolled the patients with cirrhosis who were admitted because of acute GIB from January 2010 to December 2018. Age, gender, and comorbidities were not limited.

The following data were collected: age; gender; etiology of liver cirrhosis; history of GIB, diabetes, and hepatocellular carcinoma (HCC); ascites; hepatic encephalopathy (HE); and laboratory tests at admission, mainly including hemoglobin $(\mathrm{Hb})$, hematocrit (HCT), white blood cell (WBC), platelet (PLT), total bilirubin (TBIL), albumin (ALB), alanine aminotransferase (ALT), alkaline phosphatase (AKP), gamma-glutamyl transpeptidase (GGT), serum creatinine $(\mathrm{Scr})$, potassium $(\mathrm{K})$, sodium $(\mathrm{Na})$, and international normalized ratio (INR); and in-hospital death. Child-Pugh [10], MELD [11], MELD-Na [12], and NLR [13] scores were calculated.

Random sampling was used to divide patients into training and validation cohorts with an approximate percentage of $50 \%$. Continuous variables were expressed as mean \pm standard deviation and median (range), and categorical variables were expressed as frequency (percentage). Difference between training and validation cohorts was compared by the nonparametric Mann-Whitney $U$ test and the chisquare test. In the training cohort, logistic regression analyses were performed to identify the independent predictors associated with inhospital death. Odds ratios (ORs) with 95\% confidence intervals (CIs) were calculated. An equation for predicting the death of patients with cirrhosis and acute GIB was established by merging the independent predictors with their regression coefficients. Then, receiver operating characteristic curve (ROC) analysis was performed to evaluate the predictive performance of the new equation. The area under curve (AUC) and the best cutoff value with sensitivity and specificity were calculated. The predictive performance of the new equation was also compared with other established scores (Child-Pugh [10], MELD [11], MELD-Na [12], and NLR [13] scores). All statistical analyses were performed using SPSS software version 20.0 (IBM Corp, Armonk, NY, USA) and MedCalc software version 11.4.2.0 (MedCalc Software, Mariakerke, Belgium). $P<0.05$ was considered statistically significant.

\section{RESULTS}

\section{Patient Selection}

A total of 1682 patients with cirrhosis and acute GIB were included, of whom 865 and 817 patients were enrolled into the training and validation cohorts, respectively. Characteristics of patients are summarized in Table 1 . All but the percentage of HCC were not statistically significantly different between the training and validation cohorts (Table 1).

\section{Univariate and Multivariate Analyses in the Training Cohort}

Univariate logistic regression analyses demonstrated that HCC, diabetes, hepatic $\mathrm{C}$ virus infection, ascites, HE, WBC, TBIL, ALB, ALT, Scr, and INR were significantly associated with inhospital death (Table 2). Multivariate logistic regression analyses showed that HCC, diabetes, 
Table 1 Characteristics of patients in training and validation cohorts

\begin{tabular}{|c|c|c|c|c|c|}
\hline Variables & No. pts & Training cohort & No. pts & Validation cohort & $P$ value \\
\hline \multirow[t]{2}{*}{ Age (years) } & \multirow[t]{2}{*}{865} & $56.00(20.00-88.00)$ & \multirow[t]{2}{*}{817} & $57.00(18.00-91.00)$ & \multirow[t]{2}{*}{0.1410} \\
\hline & & $56.19 \pm 12.31$ & & $57.06 \pm 12.06$ & \\
\hline Sex (male) (\%) & 865 & $615(71.10 \%)$ & 817 & $568(69.50 \%)$ & 0.4800 \\
\hline Hepatic B virus (\%) & 865 & $442(51.10 \%)$ & 817 & $433(53.00 \%)$ & 0.4360 \\
\hline Hepatic C virus (\%) & 865 & $60(6.90 \%)$ & 817 & $48(5.90 \%)$ & 0.3750 \\
\hline Alcohol abuse (\%) & 865 & $221(25.50 \%)$ & 817 & $199(24.40 \%)$ & 0.5730 \\
\hline Autoimmune liver diseases (\%) & 865 & $47(5.40 \%)$ & 817 & $35(4.30 \%)$ & 0.2740 \\
\hline History of GIB (\%) & 865 & $482(55.70 \%)$ & 817 & $461(56.40 \%)$ & 0.7710 \\
\hline History of diabetes (\%) & 865 & $164(19.00 \%)$ & 817 & $166(20.30 \%)$ & 0.4830 \\
\hline Hepatocellular carcinoma (\%) & 865 & $127(14.70 \%)$ & 817 & $153(18.70 \%)$ & $0.0260^{*}$ \\
\hline Ascites (\%) & 865 & $452(55.30 \%)$ & 817 & $513(59.30 \%)$ & 0.0990 \\
\hline Hepatic encephalopathy (\%) & 865 & $36(4.20 \%)$ & 817 & $40(4.90 \%)$ & 0.4690 \\
\hline \multirow[t]{2}{*}{ Hemoglobin (g/L) } & \multirow[t]{2}{*}{865} & $76.00(16.00-152.00)$ & 816 & $76.00(23.00-170.00)$ & \multirow[t]{2}{*}{0.5090} \\
\hline & & $79.11 \pm 24.60$ & & $78.21 \pm 24.08$ & \\
\hline \multirow[t]{2}{*}{ Hematocrit (\%) } & \multirow[t]{2}{*}{865} & $23.60(2.74-45.90)$ & 814 & $23.40(8.70-47.00)$ & \multirow[t]{2}{*}{0.3380} \\
\hline & & $24.29 \pm 6.93$ & & $23.95 \pm 6.78$ & \\
\hline \multirow[t]{2}{*}{ White blood cell $\left(10^{9} / \mathrm{L}\right)$} & \multirow[t]{2}{*}{865} & $5.81(0.98-68.00)$ & 815 & $5.63(0.74-51.00)$ & \multirow[t]{2}{*}{0.3360} \\
\hline & & $6.75 \pm 4.73$ & & $6.69 \pm 4.80$ & \\
\hline \multirow[t]{2}{*}{ Platelet $\left(10^{9} / \mathrm{L}\right)$} & \multirow[t]{2}{*}{865} & $77.00(4.00-827.00)$ & 814 & $77.00(2.00-846.00)$ & \multirow[t]{2}{*}{0.4890} \\
\hline & & $88.93 \pm 61.38$ & & $95.42 \pm 83.36$ & \\
\hline \multirow[t]{2}{*}{ Total bilirubin $(\mu \mathrm{mol} / \mathrm{L})$} & \multirow[t]{2}{*}{863} & $23.70(4.20-518.00)$ & 816 & $22.80(2.40-449.00)$ & \multirow[t]{2}{*}{0.0680} \\
\hline & & $38.03 \pm 51.14$ & & $34.01 \pm 42.19$ & \\
\hline \multirow[t]{2}{*}{ Albumin $(\mathrm{g} / \mathrm{L})$} & \multirow[t]{2}{*}{846} & $29.00(11.70-49.80)$ & 797 & $28.80(10.10-47.20)$ & \multirow[t]{2}{*}{0.2160} \\
\hline & & $29.07 \pm 5.98$ & & $28.64 \pm 5.90$ & \\
\hline \multirow[t]{2}{*}{ Alanine aminotransferase (U/L) } & \multirow[t]{2}{*}{862} & $28.00(3.00-2651.00)$ & 815 & $26.00(4.00-1575.00)$ & \multirow[t]{2}{*}{0.0880} \\
\hline & & $52.21 \pm 147.23$ & & $41.51 \pm 86.36$ & \\
\hline \multirow[t]{2}{*}{ Aspartate aminotransferase (U/L) } & \multirow[t]{2}{*}{804} & $37.00(6.00-3182.00)$ & 768 & $35.14(6.00-1993.00)$ & \multirow[t]{2}{*}{0.2770} \\
\hline & & $78.33 \pm 216.66$ & & $64.46 \pm 120.45$ & \\
\hline \multirow[t]{2}{*}{ Alkaline phosphatase (U/L) } & \multirow[t]{2}{*}{843} & $79.78(18.00-2344.00)$ & 782 & $80.00(18.90-1320.00)$ & 0.3730 \\
\hline & & $110.71 \pm 122.35$ & & $104.32 \pm 95.26$ & \\
\hline Gamma-glutamyl transpeptidase (U/L) & 840 & $39.20(2.80-2996.00)$ & 781 & $41.00(5.00-1494.90)$ & 0.5520 \\
\hline & & $93.36 \pm 190.59$ & & $85.74 \pm 132.51$ & \\
\hline
\end{tabular}


Table 1 continued

\begin{tabular}{|c|c|c|c|c|c|}
\hline Variables & No. pts & Training cohort & No. pts & Validation cohort & $P$ value \\
\hline \multirow[t]{2}{*}{ Serum creatinine $(\mu \mathrm{mol} / \mathrm{L})$} & 865 & $65.50(7.00-372.80)$ & 817 & $65.00(11.20-303.00)$ & 0.6680 \\
\hline & & $70.96 \pm 31.13$ & & $70.99 \pm 30.20$ & \\
\hline \multirow[t]{2}{*}{ Potassium (mmol/L) } & 864 & $4.10(2.25-6.71)$ & 815 & $4.10(1.85-7.37)$ & 0.4830 \\
\hline & & $4.18 \pm 0.63$ & & $4.21 \pm 0.69$ & \\
\hline \multirow[t]{2}{*}{ Sodium $(\mathrm{mmol} / \mathrm{L})$} & 860 & $137.95(115.00-153.90)$ & 816 & $137.85(105.00-161.60)$ & 0.6360 \\
\hline & & $137.08 \pm 4.69$ & & $137.19 \pm 5.23$ & \\
\hline \multirow[t]{2}{*}{ International normalized ratio } & 860 & $1.35(0.79-7.96)$ & 804 & $1.34(0.91-4.99)$ & 0.3480 \\
\hline & & $1.45 \pm 0.42$ & & $1.43 \pm 0.37$ & \\
\hline \multirow[t]{2}{*}{ Child-Pugh score } & 841 & $8.00(5.00-15.00)$ & 784 & $8.00(5.00-13.00)$ & 0.4670 \\
\hline & & $7.91 \pm 1.81$ & & $7.82 \pm 1.78$ & \\
\hline \multirow[t]{2}{*}{ MELD score } & 858 & $7.99(-13.30$ to 38.79$)$ & 803 & $7.75(-8.13$ to 33.49$)$ & 0.3940 \\
\hline & & $8.85 \pm 5.91$ & & $8.45 \pm 5.53$ & \\
\hline \multirow[t]{2}{*}{ NLR score } & 864 & $5.07(0.40-72.92)$ & 812 & $4.86(0.51-179.80)$ & 0.4350 \\
\hline & & $6.36 \pm 5.33$ & & $6.41 \pm 7.73$ & \\
\hline In-hospital death (\%) & 865 & $29(3.40 \%)$ & 817 & $23(2.80 \%)$ & 0.5240 \\
\hline
\end{tabular}

Pts patients, GIB gastrointestinal bleeding, MELD model for end-stage liver disease, $N L R$ neutrophil to lymphocyte ratio ${ }^{*}$ Statistically significant at $P<0.05$

TBIL, ALB, ALT, and Scr were independently associated with in-hospital death (Table 2).

\section{Development of CAGIB Score}

A prognostic model called CAGIB (Cirrhosis Acute GastroIntestinal Bleeding) was established. $\mathrm{CAGIB}=$ Diabetes $($ yes $=1$, no $=0) \times$ $1.040+$ HCC $($ yes $=1$, no $=0) \times 0.974+$ TBIL $(\mu \mathrm{mol} / \mathrm{L}) \times 0.005-\mathrm{ALB} \quad(\mathrm{g} / \mathrm{L}) \times 0.091+\mathrm{ALT}$ $(\mathrm{U} / \mathrm{L}) \times 0.001+\mathrm{Scr}(\mu \mathrm{mol} / \mathrm{L}) \times 0.012-3.964$. It had an AUC of 0.829 (95\% CI 0.801-0.854, $P<0.0001$ ), and its best cutoff value was greater than -4.6646 with a sensitivity of $78.57 \%$ and a specificity of $75.52 \%$ (Fig. 1). The AUCs of Child-Pugh, MELD, MELD-Na, and NLR scores were 0.762 (95\% CI 0.732-0.791), 0.778 (95\% CI $0.748-0.806), 0.765$ (95\% CI $0.735-0.793)$, and 0.587 (95\% CI $0.553-0.620)$, respectively (Fig. 2). The difference was statistically significant between CAGIB and NLR score
$(P=0.0001)$, but not between CAGIB and Child-Pugh, MELD, or MELD-Na score.

\section{Validation of CAGIB Score}

In the validation cohort, the CAGIB score had an AUC of 0.714 (95\% CI 0.682-0.746, $P=0.0006$ ) (Fig. 3). The AUCs of Child-Pugh, MELD, MELD-Na, and NLR scores were 0.693 $(95 \% \quad$ CI $\quad 0.659-0.725), \quad 0.662 \quad(95 \% \quad$ CI $0.627-0.695), 0.660$ (95\% CI $0.626-0.694)$, and $0.538 \quad(95 \%$ CI $0.503-0.574)$, respectively (Fig. 4). The difference was statistically significant between CAGIB and NLR score $(P=0.0165)$, but not between CAGIB and Child-Pugh, MELD, or MELD-Na score.

\section{DISCUSSION}

Our study developed a new model (CAGIB score) for assessing the prognosis of patients 
Table 2 Univariate and multivariate analyses of predictors associated with the in-hospital mortality of acute GIB in training cohort

\begin{tabular}{|c|c|c|c|c|c|c|c|}
\hline \multirow[t]{2}{*}{ Variables } & \multirow{2}{*}{$\begin{array}{l}\text { No. pts } \\
(\text { all = 865) }\end{array}$} & \multicolumn{3}{|c|}{ Univariate } & \multicolumn{3}{|c|}{ Multivariate } \\
\hline & & $\overline{\text { OR }}$ & $95 \% \mathrm{CI}$ & $P$ value & $\overline{\mathrm{OR}}$ & 95\% CI & $P$ value \\
\hline Age (years) & 865 & 1.029 & $0.998-1.061$ & 0.0670 & & & \\
\hline Sex (female vs. male) & 865 & 1.288 & $0.543-3.054$ & 0.5660 & & & \\
\hline Hepatic B virus (yes vs. no) & 865 & 1.124 & $0.536-2.358$ & 0.7570 & & & \\
\hline Hepatic $\mathrm{C}$ virus (yes vs. no) & 865 & 3.778 & $1.476-9.670$ & $0.0060^{*}$ & 2.794 & $0.917-8.512$ & 0.0710 \\
\hline Alcohol abuse (yes vs. no) & 865 & 1.325 & $0.594-2.954$ & 0.4920 & & & \\
\hline Autoimmune (yes vs. no) & 865 & 1.630 & $0.217-12.250$ & 0.6800 & & & \\
\hline History of GIB (yes vs. no) & 865 & 1.573 & $0.747-3.311$ & 0.2330 & & & \\
\hline History of diabetes (yes vs. no) & 865 & 2.728 & $1.263-5.894$ & $0.0110^{*}$ & 2.824 & $1.127-7.079$ & $0.0270^{*}$ \\
\hline $\begin{array}{l}\text { Hepatocellular carcinoma (yes vs. } \\
\text { no) }\end{array}$ & 865 & 2.738 & $1.218-6.158$ & $0.0150^{*}$ & 2.647 & $1.022-6.859$ & $0.0450^{*}$ \\
\hline Ascites (yes vs. no) & 865 & 2.707 & $1.091-6.718$ & $0.0320^{*}$ & 1.995 & $0.713-5.586$ & 0.1880 \\
\hline $\begin{array}{l}\text { Hepatic encephalopathy (yes vs. } \\
\text { no) }\end{array}$ & 865 & 4.020 & $1.321-12.235$ & $0.0140^{*}$ & 2.147 & $0.562-8.210$ & 0.2640 \\
\hline Hemoglobin $(\mathrm{g} / \mathrm{L})$ & 865 & 0.995 & $0.980-1.011$ & 0.5280 & & & \\
\hline Hematocrit $(\%)$ & 865 & 0.965 & $0.912-1.020$ & 0.2040 & & & \\
\hline White blood cell $\left(10^{9} / \mathrm{L}\right)$ & 865 & 1.054 & $1.005-1.104$ & $0.0290^{*}$ & 1.020 & $0.964-1.078$ & 0.5000 \\
\hline Platelet $\left(10^{9} / \mathrm{L}\right)$ & 865 & 1.003 & $0.999-1.007$ & 0.1580 & & & \\
\hline Total bilirubin $(\mu \mathrm{mol} / \mathrm{L})$ & 863 & 1.008 & $1.004-1.011$ & $<0.0001^{*}$ & 1.005 & $1.001-1.009$ & $0.0200^{*}$ \\
\hline Albumin $(\mathrm{g} / \mathrm{L})$ & 846 & 0.874 & $0.815-0.936$ & $<0.0001^{*}$ & 0.912 & $0.840-0.989$ & $0.0260^{*}$ \\
\hline Alanine aminotransferase (U/L) & 862 & 1.002 & $1.001-1.003$ & $0.0040^{*}$ & 1.001 & $1.000-1.002$ & $0.0490^{*}$ \\
\hline $\begin{array}{l}\text { Aspartate aminotransferase (U/ } \\
\mathrm{L})^{\mathrm{b}}\end{array}$ & 804 & 1.001 & $1.000-1.002$ & $0.0060^{*}$ & & & \\
\hline Alkaline phosphatase (U/L) & 843 & 1.001 & $1.000-1.003$ & 0.0750 & & & \\
\hline $\begin{array}{l}\text { Gamma-glutamyl transpeptidase } \\
(\mathrm{U} / \mathrm{L})\end{array}$ & 840 & 1.000 & $0.999-1.002$ & 0.6560 & & & \\
\hline Serum creatinine $(\mu \mathrm{mol} / \mathrm{L})$ & 865 & 1.012 & $1.005-1.018$ & $<0.0001^{*}$ & 1.012 & $1.004-1.020$ & $0.0040^{*}$ \\
\hline Potassium (mmol/L) & 864 & 1.323 & $0.765-2.289$ & 0.3160 & & & \\
\hline Sodium $(\mathrm{mmol} / \mathrm{L})$ & 860 & 0.940 & $0.877-1.007$ & 0.0790 & & & \\
\hline International normalized ratio & 860 & 2.320 & $1.310-4.110$ & $0.0040^{*}$ & 1.311 & $0.737-2.335$ & 0.3570 \\
\hline Child-Pugh score ${ }^{\mathrm{a}}$ & 841 & 1.652 & $1.358-2.009$ & $<0.0001^{*}$ & & & \\
\hline MELD score ${ }^{a}$ & 858 & 1.149 & $1.095-1.205$ & $<0.0001^{*}$ & & & \\
\hline
\end{tabular}


Table 2 continued

\begin{tabular}{|c|c|c|c|c|c|c|c|}
\hline \multirow[t]{2}{*}{ Variables } & \multirow{2}{*}{$\begin{array}{l}\text { No. pts } \\
(\text { all }=865)\end{array}$} & \multicolumn{3}{|c|}{ Univariate } & \multicolumn{3}{|c|}{ Multivariate } \\
\hline & & OR & $95 \% \mathrm{CI}$ & $P$ value & OR & $95 \% \mathrm{CI}$ & $P$ value \\
\hline NLR score ${ }^{a}$ & 864 & 1.042 & $0.998-1.088$ & 0.0640 & & & \\
\hline
\end{tabular}

Pts patients, GIB gastrointestinal bleeding, MELD model for end-stage liver disease, $N L R$ neutrophil to lymphocyte ratio * Statistically significant at $P<0.05$

a Child-Pugh score, MELD score, and NLR score are complex variables composed of many clinically significant variables, so they were not included in the multivariate analysis

b Aspartate aminotransferase and alanine aminotransferase had a potential collinearity for assessing liver dysfunction, so we excluded the aspartate aminotransferase in multivariate analysis

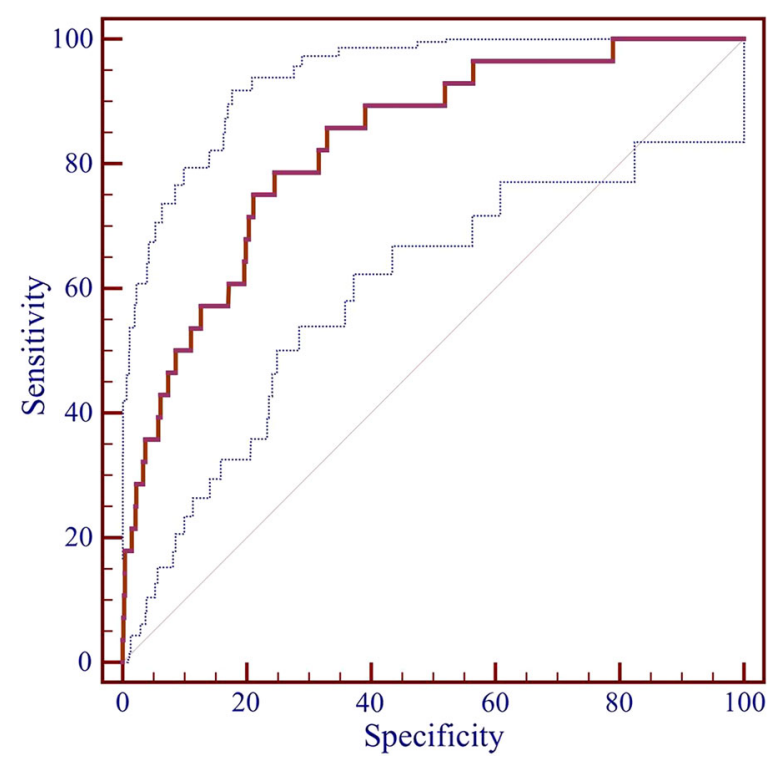

Fig. 1 ROC curve of CAGIB score for predicting the inhospital death of patients with cirrhosis and acute GIB in the training cohort

with cirrhosis and acute GIB. Our study has the following notable features: (1) the data was obtained from multiple institutions in China; (2) a large number of patients were included; (3) the variables used for this model were readily available in clinical practice; (4) CAGIB score had a greater predictive performance than other conventional models in both training and validation cohorts; and (5) the predictive performance of CAGIB score was further validated.

CAGIB score includes two clinical variables (i.e., diabetes and HCC). Diabetes is a worldwide pandemic with a prevalence of $9.4 \%$ in the USA [14] and $11.6 \%$ in China [15]. Increasing

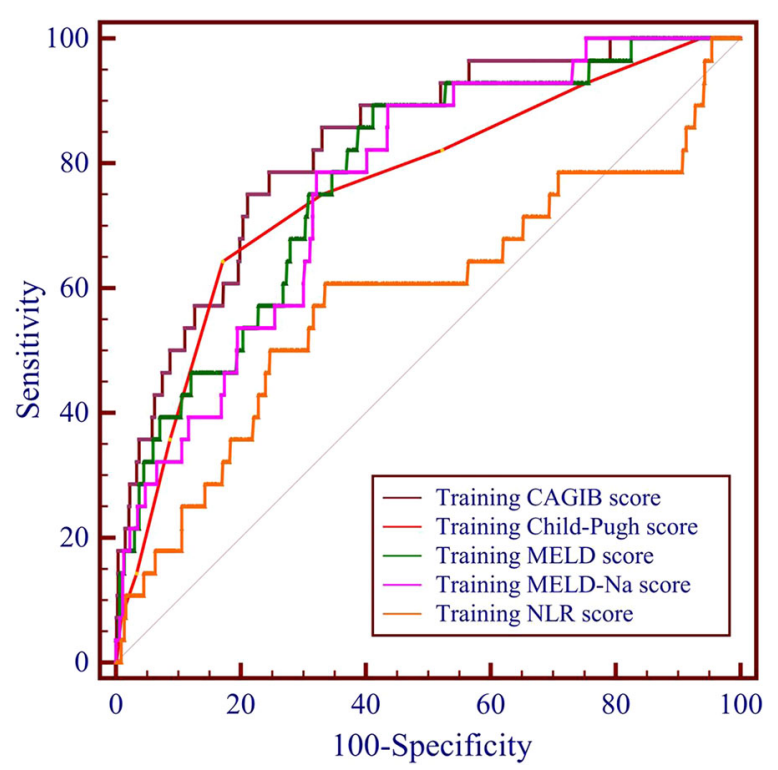

Fig. 2 Comparison of predictive performance of CAGIB score with Child-Pugh, MELD, MELD-Na and NLR scores in the training cohort. Brown line refers to the CAGIB score, red line refers to the Child-Pugh score, green line refers to the MELD score, purple line refers to the MELD-Na score, and orange line refers to the NLR score

evidence suggests a close relationship between diabetes and outcomes of liver disease. Diabetes increased the risks of liver cancer and chronic liver diseases [16-18] and was also associated with an increased risk of mortality in patients with cirrhosis [19]. Our previous single-center study also showed that diabetes was significantly associated with the prognosis of patients with cirrhosis and acute upper GIB, which is consistent with our current study [20]. On the other hand, HCC is one of the most common 


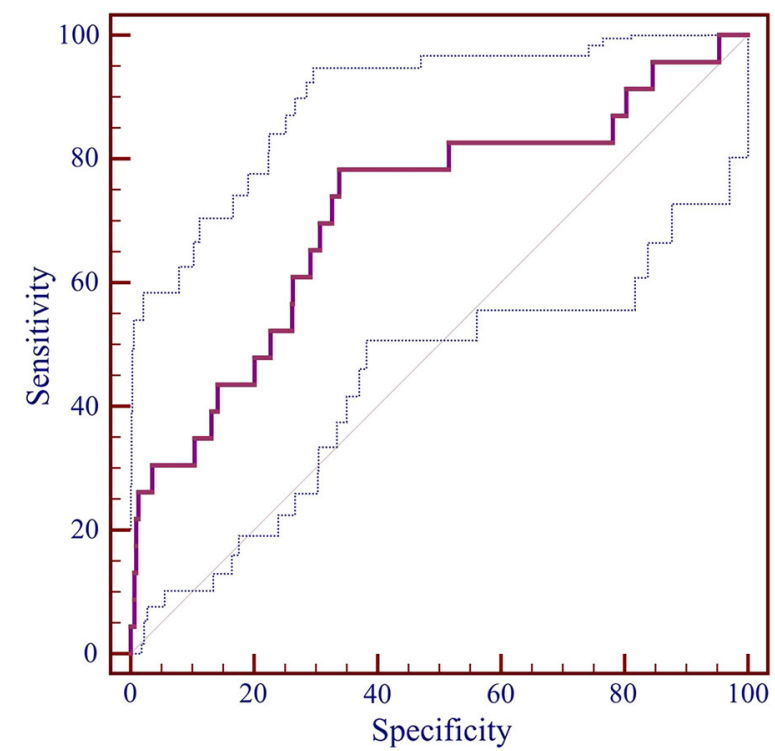

Fig. 3 ROC curve of CAGIB score for predicting the inhospital death of patients with cirrhosis and acute GIB in the validation cohort

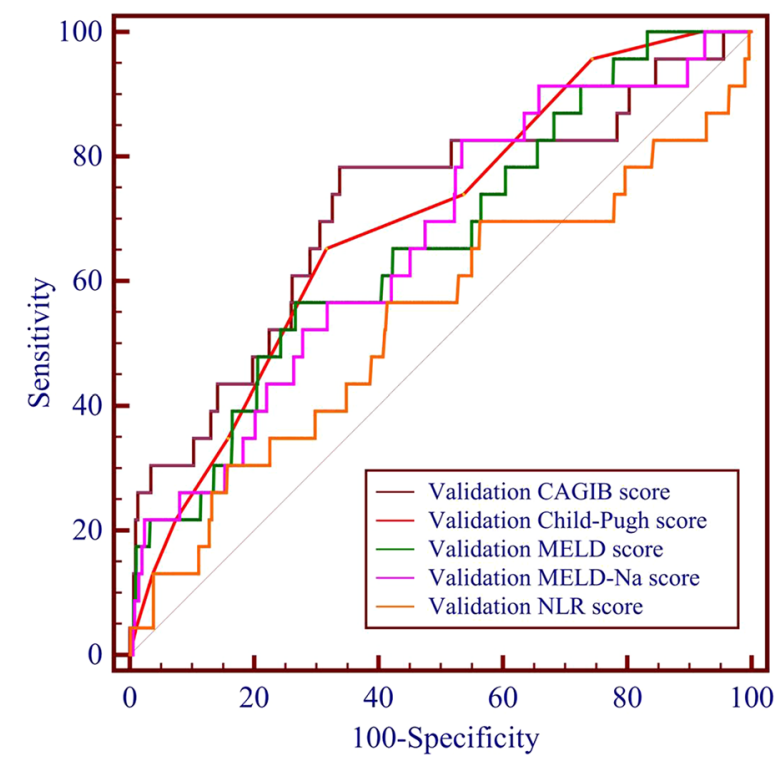

Fig. 4 Comparison of predictive performance of CAGIB score with Child-Pugh, MELD, MELD-Na and NLR scores in the validation cohort. Brown line refers to the CAGIB score, red line refers to the Child-Pugh score, green line refers to the MELD score, purple line refers to the MELD-Na score, and orange line refers to the NLR score

causes of cancer-related death [21]. And $80 \%$ of HCC patients have liver cirrhosis [22]. HCC can further aggravate portal pressure due to tumor compression and tumor thrombus formation and is considered as the independent predictor of death and re-bleeding in patients with cirrhosis and GIB [9, 23-25].

CAGIB score also includes four laboratory variables (i.e., TBIL, ALB, Scr, and ALT). Inclusion of TBIL, ALB, and Scr into this new model is easily understood, because they are important components of conventional scoring systems (i.e., MELD and Child-Pugh scores). Notably, a rapid increase in Scr level is often an acute critical condition indicating decreased kidney perfusion in patients with cirrhosis developing an acute GIB episode. Indeed, regardless of acute GIB, renal failure increases the mortality sevenfold in patients with cirrhosis [26]. In patients with cirrhosis and acute GIB, acute kidney injury is also an independent predictor for death [5, 27]. Besides, our study found that an increased ALT level was another independent predictor. In patients with cirrhosis and massive GIB, nearly all organs, including liver, are in an ischemic state after acute blood loss [28]. Hypoxic hepatitis, which is characterized by a rapid rise in serum aminotransferases due to liver cell necrosis by mitochondrial damage and DNA fragmentation [29], can be frequently observed in patients with cirrhosis and variceal bleeding [30] and negatively influence the patients' outcomes [31].

A major limitation was that CAGIB score could not be compared with conventional scoring systems for GIB, such as Rockall, GBS, and AIMS65 scores, because not all patients underwent endoscopy. Second, for some patients, the source of GIB was unclear due to lack of the relevant endoscopy data. Thus, the association of sources of acute GIB with the mortality was not explored in the current study. Third, the stage of HCC was not extracted in our study. Fourth, the potential heterogeneity in the treatment selection among the participating centers should be acknowledged.

\section{CONCLUSIONS}

We developed and validated the CAGIB score to predict the in-hospital death of patients with cirrhosis and acute GIB. A CAGIB score of greater than -4.6646 suggested a high risk of 
in-hospital death in liver cirrhosis with acute GIB. On the basis of the CAGIB score, physicians may also pay attention to the management of diabetes, improvement of liver and renal function, and supplementation of human albumin solution for patients with cirrhosis and acute GIB.

\section{ACKNOWLEDGEMENTS}

We thank the participants of the study.

Funding. No funding or sponsorship was received for this study or publication of this article.

Authorship. All named authors meet the International Committee of Medical Journal Editors (ICMJE) criteria for authorship for this article, take responsibility for the integrity of the work as a whole, and have given their approval for this version to be published.

Authorship Contributions. Zhaohui Bai: collected the data, analyzed the data, performed the statistical analysis, and drafted manuscript. Bimin Li, Su Lin, Bang Liu, Yiling Li, Qiang Zhu, Yunhai Wu, Yida Yang, Shanhong Tang, Fanping Meng, Yu Chen, Shanshan Yuan, and Lichun Shao: collected the data, analyzed the data, and gave critical comments. Xingshun Qi: conceived the work, wrote the study protocol, reviewed the literature, gave critical comments, and revised the manuscript. All authors reviewed and approved the paper.

Disclosures. All authors, including Zhaohui Bai, Bimin Li, Su Lin, Bang Liu, Yiling Li, Qiang Zhu, Yunhai Wu, Yida Yang, Shanhong Tang, Fanping Meng, Yu Chen, Shanshan Yuan, Lichun Shao, and Xingshun Qi, have nothing to disclose.

Compliance with Ethics Guidelines. The present study was carried out following the rules of the Declaration of Helsinki and approved by the Medical Ethical Committee of the General Hospital of Northern Theater Command (formerly General Hospital of Shenyang Military Area), which is the principal affiliation of this study. The ethical approval number was $\mathrm{k}(2019)$ 20. Considering the nature of this observational study, the patients' written informed consent was waived by the ethics committee.

Data Availability. The datasets generated during and/or analyzed during the current study are available from the corresponding author on reasonable request.

Open Access. This article is distributed under the terms of the Creative Commons Attribution-NonCommercial 4.0 International License (http://creativecommons.org/licenses/ by-nc/4.0/), which permits any noncommercial use, distribution, and reproduction in any medium, provided you give appropriate credit to the original author(s) and the source, provide a link to the Creative Commons license, and indicate if changes were made.

\section{REFERENCES}

1. Abougergi MS, Travis AC, Saltzman JR. The in-hospital mortality rate for upper GI hemorrhage has decreased over 2 decades in the United States: a nationwide analysis. Gastrointest Endosc. 2015; 81(4):882-8 (e1).

2. Jairath V, Martel M, Logan RF, Barkun AN. Why do mortality rates for nonvariceal upper gastrointestinal bleeding differ around the world? A systematic review of cohort studies. Can J Gastroenterol. 2012; 26(8):537-43.

3. Garcia-Tsao G, Bosch J. Management of varices and variceal hemorrhage in cirrhosis. N Engl J Med. 2010;362(9):823-32.

4. Li Y, Han B, Li H, et al. Effect of admission time on the outcomes of liver cirrhosis with acute upper gastrointestinal bleeding: regular hours versus off-hours admission. Can J Gastroenterol Hepatol. 2018; 2018:3541365.

5. Ardevol A, Ibanez-Sanz G, Profitos J, et al. Survival of patients with cirrhosis and acute peptic ulcer bleeding compared with variceal bleeding using current first-line therapies. Hepatology. 2018;67(4): 1458-71.

6. Rockall TA, Logan RF, Devlin HB, Northfield TC. Risk assessment after acute upper gastrointestinal haemorrhage. Gut. 1996;38(3):316-21. 
7. Blatchford O, Davidson LA, Murray WR, Blatchford $\mathrm{M}$, Pell J. Acute upper gastrointestinal haemorrhage in west of Scotland: case ascertainment study. BMJ. 1997;315(7107):510-4.

8. Saltzman JR, Tabak YP, Hyett BH, Sun X, Travis AC, Johannes RS. A simple risk score accurately predicts in-hospital mortality, length of stay, and cost in acute upper GI bleeding. Gastrointest Endosc. 2011;74(6):1215-24.

9. D'Amico G, De Franchis R, Cooperative Study Group. Upper digestive bleeding in cirrhosis. Posttherapeutic outcome and prognostic indicators. Hepatology. 2003;38(3):599-612.

10. Peng Y, Qi X, Dai J, Li H, Guo X. Child-Pugh versus MELD score for predicting the in-hospital mortality of acute upper gastrointestinal bleeding in liver cirrhosis. Int J Clin Exp Med. 2015;8(1):751-7.

11. Peng Y, Qi X, Guo X. Child-Pugh versus MELD score for the assessment of prognosis in liver cirrhosis: $a$ systematic review and meta-analysis of observational studies. Medicine (Baltimore). 2016;95(8):e2877.

12. Coakley KM, Sarasani S, Prasad T, et al. MELD-Na score as a predictor of anastomotic leak in elective colorectal surgery. J Surg Res. 2018;232:43-8.

13. Peng Y, Li Y, He Y, et al. The role of neutrophil to lymphocyte ratio for the assessment of liver fibrosis and cirrhosis: a systematic review. Expert Rev Gastroenterol Hepatol. 2018;12(5):503-13.

14. American Diabetes Association. Statistics about diabetes overall numbers, diabetes and prediabetes. http://www.diabetes.org/diabetes-basics/statistics. Accessed 22 July 2019.

15. Xu Y, Wang L, He J, et al. Prevalence and control of diabetes in Chinese adults. JAMA. 2013;310(9) :948-59.

16. Pang Y, Kartsonaki C, Turnbull I, et al. Diabetes, plasma glucose, and incidence of fatty liver, cirrhosis, and liver cancer: a prospective study of 0.5 million people. Hepatology. 2018;68(4):1308-18.

17. Flores YN, Lang CM, Salmeron J, Bastani R. Risk factors for liver disease and associated knowledge and practices among Mexican adults in the US and Mexico. J Community Health. 2012;37(2):403-11.

18. Davis TM, Peters KE, Bruce DG, Davis WA. Prevalence, incidence, and prognosis of hepatobiliary disease in community-based patients with type 2 diabetes: the Fremantle Diabetes Study. J Clin Endocrinol Metab. 2012;97(5):1581-8.

19. Goh GB, Pan A, Chow WC, Yuan JM, Koh WP. Association between diabetes mellitus and cirrhosis mortality: the Singapore Chinese Health Study. Liver Int. 2017;37(2):251-8.

20. Qi X, Peng Y, Li H, Dai J, Guo X. Diabetes is associated with an increased risk of in-hospital mortality in liver cirrhosis with acute upper gastrointestinal bleeding. Eur J Gastroenterol Hepatol. 2015;27(4):476-7.

21. Bray F, Ferlay J, Soerjomataram I, Siegel RL, Torre LA, Jemal A. Global cancer statistics 2018: GLOBOCAN estimates of incidence and mortality worldwide for 36 cancers in 185 countries. CA Cancer J Clin. 2018;68(6):394-424.

22. Coskun M. Hepatocellular carcinoma in the cirrhotic liver: evaluation using computed tomography and magnetic resonance imaging. Exp Clin Transpl. 2017;15(Suppl 2):36-44.

23. Singal AK, Jampana SC, Singal V, Kuo YF. Hepatocellular carcinoma predicts in-hospital mortality from acute variceal hemorrhage among patients with cirrhosis. J Clin Gastroenterol. 2012;46(7):613-9.

24. Chen CH, Sheu JC, Huang GT, et al. Characteristics of hepatocellular carcinoma presenting with variceal bleeding. J Gastroenterol Hepatol. 1998;13 (2):170-4.

25. Jiang JF, Lao YC, Yuan BH, et al. Treatment of hepatocellular carcinoma with portal vein tumor thrombus: advances and challenges. Oncotarget. 2017;8(20):33911-21.

26. Fede G, D'Amico G, Arvaniti V, et al. Renal failure and cirrhosis: a systematic review of mortality and prognosis. J Hepatol. 2012;56(4):810-8.

27. Cardenas A, Gines P, Uriz J, et al. Renal failure after upper gastrointestinal bleeding in cirrhosis: incidence, clinical course, predictive factors, and shortterm prognosis. Hepatology. 2001;34(4 Pt 1):671-6.

28. Lasa JS, Moore R, Arguello M, et al. Hypovolemic shock due to gastric variceal bleeding. Acta Gastroenterol Latinoam. 2013;43(1):6 (79).

29. Weemhoff JL, Woolbright BL, Jenkins RE, et al. Plasma biomarkers to study mechanisms of liver injury in patients with hypoxic hepatitis. Liver Int. 2017;37(3):377-84.

30. Amitrano L, Guardascione MA, Martino R, Manguso F, Menchise A, Balzano A. Hypoxic hepatitis occurring in cirrhosis after variceal bleeding: still a lethal disease. J Clin Gastroenterol. 2012;46(7):608-12.

31. Waseem N, Chen PH. Hypoxic hepatitis: a review and clinical update. J Clin Transl Hepatol. 2016;4(3):263-8. 